\title{
Tricarboxylic Acid (TCA) Cycle Enzymes and Intermediates Modulate Intracellular Cyclic di-GMP Levels and the Production of Plant Cell Wall-Degrading Enzymes in Soft Rot Pathogen Dickeya dadantii
}

\author{
Xiaochen Yuan, ${ }^{1,2}$ Quan Zeng, ${ }^{3}$ Jingsheng Xu, ${ }^{4}$ Geoffrey B. Severin, ${ }^{5}$ Xiang Zhou, ${ }^{6}$ \\ Christopher M. Waters, ${ }^{7}$ George W. Sundin, ${ }^{8}$ Abasiofiok M. Ibekwe, ${ }^{9}$ Fengquan Liu, ${ }^{1, \dagger}$ \\ and Ching-Hong Yang ${ }^{2, \dagger}$ \\ ${ }^{1}$ Institute of Plant Protection, Jiangsu Academy of Agricultural Sciences, Jiangsu Key Laboratory for Food Quality and Safety- \\ State Key Laboratory Cultivation Base of Ministry of Science and Technology, Nanjing, 210014, China \\ ${ }^{2}$ Department of Biological Sciences, University of Wisconsin-Milwaukee, Milwaukee, WI 53211, U.S.A. \\ ${ }^{3}$ Department of Plant Pathology and Ecology, The Connecticut Agricultural Experiment Station, New Haven, CT 06511, U.S.A. \\ ${ }^{4}$ Institute of Plant Protection, Chinese Academy of Agricultural Sciences, Beijing, 100193, China \\ ${ }^{5}$ Department of Biochemistry and Molecular Biology, Michigan State University, East Lansing, MI 48824, U.S.A. \\ ${ }^{6}$ School of Forestry and Biotechnology, Zhejiang Agricultural and Forestry University, Hangzhou, 311300, China \\ ${ }^{7}$ Department of Microbiology and Molecular Genetics, Michigan State University \\ ${ }^{8}$ Department of Plant, Soil, and Microbial Sciences, Michigan State University \\ ${ }^{9}$ Agricultural Research Service-US Salinity Laboratory, United States Department of Agriculture, Riverside, CA 92507, U.S.A.
}

Accepted 8 October 2019.

Dickeya dadantii is a plant-pathogenic bacterium that causes soft-rot in a wide range of plants. Although we have previously demonstrated that cyclic bis-( $\left.3^{\prime}-5^{\prime}\right)$-cyclic dimeric guanosine monophosphate (c-di-GMP), a bacterial secondary messenger, plays a central role in virulence regulation in $D$. dadantii, the upstream signals that modulate c-di-GMP remain enigmatic. Using a genome-wide transposon mutagenesis approach of a $\Delta h f q$ mutant strain that has high c-di-GMP and reduced motility, we uncovered transposon mutants that recovered the c-di-GMP-mediated repression on swimming motility. A number of these mutants harbored transposon insertions in genes encoding tricarboxylic acid (TCA) cycle enzymes. Two of these TCA transposon mutants were studied further by generating chromosomal deletions of the fumA gene (encoding fumarase)

Present address of X. Yuan: Department of Plant, Soil, and Microbial Sciences, Michigan State University, East Lansing, MI 48824, U.S.A.

${ }^{\dagger}$ Corresponding authors: F. Liu; fqliu20011@sina.com;

and C.-H. Yang; chyang@uwm.edu

Funding: X. Yuan was supported by the Postdoctoral Workstation of Jiangsu Academy of Agricultural Sciences. This work was funded by United States Department of Agriculture-National Institute of Food and Agriculture (USDA-NIFA) Exploratory Research (2016-67030-24856 to Q. Zeng and C.-H. Yang), USDA-NIFA Organic Transitions (2017-5110627001 to Q. Zeng, B. T. Steven, G. W. Sundin, J. C. White, and C.-H. Yang], Research Growth Initiative of the University of Wisconsin-Milwaukee (C.-H. Yang), National Institutes of Health grants (GM109259 and AI130554 to C. M. Waters, and the Earmarked Fund for China Agriculture Research System (CARS-28-16 to F. Liu).

*The $e$-Xtra logo stands for "electronic extra" and indicates that three supplementary figures are published online.

The author(s) declare no conflict of interest.

๑) 2020 The American Phytopathological Society and the $s d h C D A B$ operon (encoding succinate dehydrogenase). Disruption of the TCA cycle in these deletion mutants resulted in reduced intracellular c-di-GMP and enhanced production of pectate lyases (Pels), a major plant cell wall-degrading enzyme (PCWDE) known to be transcriptionally repressed by c-diGMP. Consistent with this result, addition of TCA cycle intermediates such as citrate also resulted in increased c-di-GMP levels and decreased production of Pels. Additionally, we found that a diguanylate cyclase GcpA was solely responsible for the observed citrate-mediated modulation of c-di-GMP. Finally, we demonstrated that addition of citrate induced not only an overproduction of GcpA protein but also a concomitant repression of the c-di-GMP-degrading phosphodiesterase EGcpB which, together, resulted in an increase in the intracellular concentration of c-di-GMP. In summary, our report demonstrates that bacterial respiration and respiration metabolites serve as signals for the regulation of c-di-GMP signaling.

Keywords: bacterial pathogenesis, c-di-GMP, cell wall, Dickeya dadantii, metabolism, pectate lyase, soft rot, TCA cycle

Dickeya dadantii is a phytopathogenic enterobacterium that causes soft-rot, wilt, and blight diseases in a wide range of economically-important vegetables and crops (Czajkowski et al. 2011; Ma et al. 2007). To successfully infect a plant host, D. dadantii coordinately expresses a panel of virulence-related genes encoding the plant cell wall-degrading enzymes (PCWDE), the type III secretion system (T3SS), flagellar motility, and biofilm formation (Alfano and Collmer 1997; Antúnez-Lamas et al. 2009; Bauer et al. 1994; Collmer and Keen 1986; Hugouvieux-Cotte-Pattat et al. 2014; Jahn et al. 2011; Río-Álvarez et al. 2015; Yang et al. 2002). Because D. dadantii can survive in soil and ground water and has a wide host range, it must also be prepared to navigate dynamic environmental and host conditions (Czajkowski et al. 2011). To 
adapt to these changing environments, $D$. dadantii maintains a sophisticated regulatory network to control the expression level of virulence-related genes (Yang et al. 2008; Yi et al. 2010; Yuan et al. 2018, 2019; Zeng et al. 2010). One of the most critical and well-studied nodes of this network is bis- $\left(3^{\prime}-5^{\prime}\right)$ cyclic dimeric guanosine monophosphate (c-di-GMP).

c-di-GMP is a ubiquitous bacterial second messenger in the Enterobacteriaceae family that promotes the transition from a motile to sessile lifestyle (Römling et al. 2013). It is a global regulator of many different phenotypes, including motility, biofilm formation, and virulence. In $D$. dadantii, c-di-GMP plays a central role in modulating virulence-related gene expression as it represses flagellar motility, PCWDE production, and the T3SS while promoting biofilm formation (Yi et al. 2010; Yuan et al. 2015). c-di-GMP metabolism is dependent on the GGDEF domain-containing diguanylate cyclase (DGC) enzymes and the EAL or HD-GYP domain-containing phosphodiesterase (PDE) enzymes. DGCs convert two molecules of guanosine-5' -triphosphate (GTP) to c-di-GMP (Paul et al. 2004; Whiteley and Lee 2015), whereas PDEs degrade c-diGMP to 5'-phosphoguanylyl-(3'-5')-guanosine or to two molecules of guanosine monophosphate (GMP) by the EAL and HD-GYP domains, respectively (Ryan et al. 2006; Schmidt et al. 2005; Tamayo et al. 2005). In D. dadantii 3937, 12 GGDEF-domain proteins, four EAL-domain proteins, and two GGDEF and EAL dual-domain proteins were identified (Yuan et al. 2018), among which a DGC named GcpA and the PDE EGcpB were found to regulate flagellar motility and the production of pectate lyases (Pels). By synthesizing and hydrolyzing the intracellular c-di-GMP levels, GcpA and EGcpB negatively and positively control motility through $h n s$, which encodes a nucleoid-structuring protein. GcpA and EGcpB also negatively and positively modulate the production of Pels, through the control of a regulatory small RNA RsmB. Additionally, two regulatory proteins containing c-di-GMP-binding PilZ domains, YcgR and $\mathrm{BcsA}$, have been shown to regulate swimming motility, biofilm formation, T3SS, and Pel production (Yuan et al. 2015).

Although the enzymes involved in c-di-GMP metabolism and downstream regulatory targets have been well characterized, the upstream environmental and intracellular signals that regulate the abundance and activity of these enzymes remain a mystery. In this study, we sought to identify regulators and signals in $D$. dadantii that positively modulate the intracellular levels of c-di-GMP. To this end, we performed genome-wide random transposon mutagenesis in a $\Delta h f q D$. dadantii background, which contains an enhanced basal level of c-di-GMP, and screened for mutants with a restored swimming motility. Multiple mutants with restored swimming phenotypes were found to have transposon insertions in genes involved in the tricarboxylic acid (TCA) cycle, such as succinate dehydrogenase, fumarase, and malate dehydrogenase. The impact of the TCA on c-di-GMP metabolism was further investigated by generating deletion mutants of the $s d h C D A B$ operon and fumA gene encoding succinate dehydrogenase and fumarase, respectively. Introduction of these TCA mutants resulted in decreased intracellular c-di-GMP as well as increased swimming motility and Pel production. In addition to mutagenesis of key enzymes or enzyme complexes involved in biosynthesis of TCA intermediates, we also demonstrated that c-di-GMP and downstream phenotypes can be modulated by adding exogenous TCA intermediates, particularly citrate, into bacterial culture. Addition of exogenous citrate enhanced the GcpAmediated repression on Pel by upregulating the DGC GcpA and downregulating the PDE EGcpB. In summary, our study demonstrated that $D$. dadantii can sense the levels of TCA cycle intermediates and use this signal to coordinate virulence gene expression through c-di-GMP signaling. These results expand our knowledge of c-di-GMP regulatory inputs and emphasize the important role of this secondary messenger in virulence and lifestyle modulation.

\section{RESULTS}

\section{Genome-wide identification of positive regulators of intracellular c-di-GMP levels.}

To identify regulators of c-di-GMP in $D$. dadantii, we performed a transposon mutagenesis screen in D. dadantii $\Delta h f q$. We chose to perform the screen in the $\Delta h f q$ background instead of the wild type because Hfq was previously characterized as a negative regulator of intracellular c-di-GMP (Yuan et al. 2019). Deletion of $h f q$ resulted in elevated c-di-GMP levels and a complete abolishment of flagellar motility on a soft agar swimming plate. We hypothesize that a restoration of flagellar motility following transposon mutagenesis in the $\Delta h f q$ strain would facilitate the identification of genes that positively regulate c-di-GMP. In total, 10, 000 transposon insertion mutants, corresponding to an average coverage of 2.2 transposon insertions per gene, were generated using a mariner transposon miniHimar RB1 (Bouhenni et al. 2005) in D. dadantii $\Delta h f q$. In a high-throughput fashion, these mutants were tested for their capacity to swim in soft agar relative to the parental $\Delta h f q$ strain, leading to the identification of 56 transposon insertion mutants that demonstrated a restoration of swimming motility. Among them, three mutants had the transposons inserted in different locations within the open reading frame (ORF) of gcpA, which encodes a DGC (Fig. 1A). Because GcpA is directly responsible for c-di-GMP biosynthesis and a negative regulator of swimming motility (Yuan et al. 2018), identification of mutations in gcpA which resulted in the restoration of flagellar motility validated our transposon mutagenesis and screening method.

Interestingly, eight of the remaining 53 transposon mutants that displayed restored swimming motility under elevated c-diGMP conditions had the transposon inserted in several genes linked to the TCA cycle (Fig. 1B to E). One mutant had the

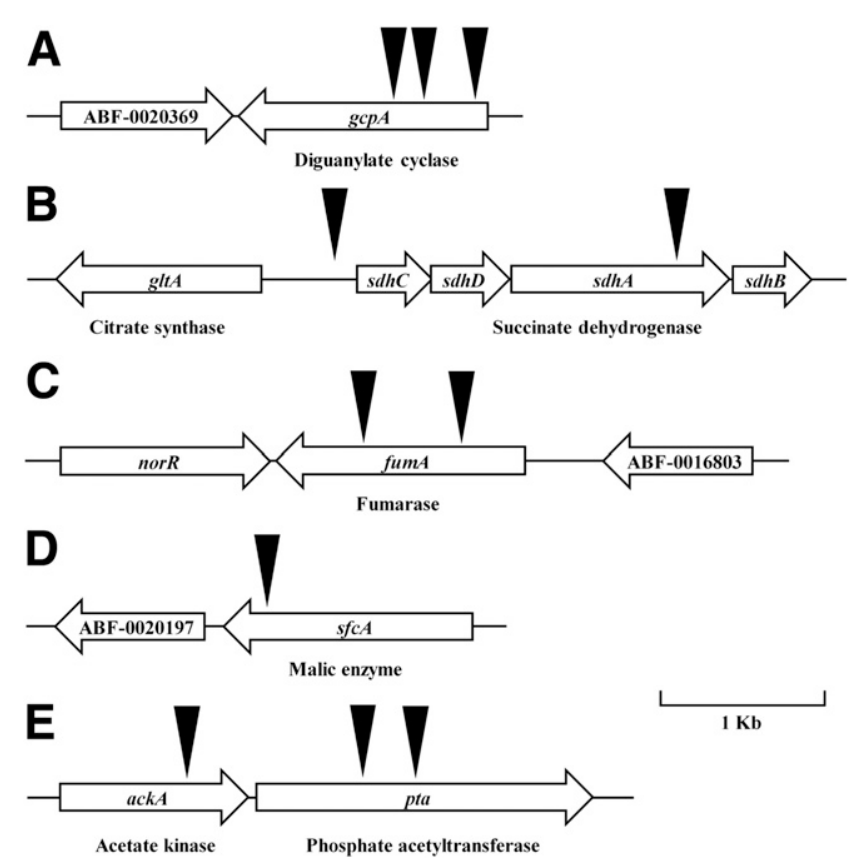

Fig. 1. Schematic drawing of the selected transposon insertions. A to E, Black arrows indicate the transposon insertion sites. 
transposon inserted in gene $s d h A$ of the $s d h C D A B$ operon, which encodes succinate dehydrogenase, an enzyme complex that catalyzes the conversion of succinate to fumarate (Fig. 1B). One mutant had a transposon inserted in the intergenic region between gltA, which encodes a citrate synthase, and the $s d h C D A B$ operon (Fig. 1B). Two mutants had transposons inserted in different locations of fumA, which encodes a fumarase that catalyzes the reversible hydration of fumarate to malate (Fig. 1C). One mutant had the transposon inserted in a malate dehydrogenase gene $s f c A$ (Fig. 1D). Three mutants had transposons inserted in genes for acetate kinase (ackA) and phosphate acetyltransferase ( $p t a)$, which encode enzymes involved in the interconversion of acetate and acetyl-CoA (Fig. $1 \mathrm{E})$. Transposon mutations of the $s d h C D A B$ operon or fumA gene showed the most significant increase of the swimming motility in $\Delta h f q$ relative to other mutations (data not shown). To validate the swimming phenotype observed in the transposon mutants, we chromosomally deleted $s d h C D A B$ or fumA in the $h f q$ mutant background ( $\Delta s d h C D A B \Delta h f q$ and $\Delta f u m A \Delta h f q)$. As expected, the swimming motility of these two strains increased by 1.3 - and 1.5 -fold, respectively, relative to $\Delta h f q$ (Fig. 2A).

\section{Impact of $s d h C D A B$ and fumA deletions on citrate metabolism.}

Succinate dehydrogenase (encoded by $s d h C D A B$ ) and fumarase (encoded by fumA) are important anaplerotic enzymes for the TCA cycle in bacteria (Shimizu 2013; Takeuchi et al. 2009). Without these enzymes, the ability to utilize citrate to produce adenosine triphosphate and the reduced form of nicotinamide adenine dinucleotide would be greatly compromised and, therefore, would result in retarded growth when citrate was used as the sole carbon source. To confirm that $s d h C D A B$ and fumA truly function as anaplerotic enzymes in the TCA cycle in $D$. dadantii, we measured growth of the wild type and of the $\triangle s d h C D A B$ and $\triangle$ fumA mutants in the complex medium lysogeny broth (LB) and in M9 minimal medium (MM) supplemented with citrate as the sole carbon source. When cultured in LB broth, all three strains grew to approximately the same yield, with only $\triangle s d h C D A B$ demonstrating a modest reduction in its exponential growth, likely due to an impaired TCA cycle
(Fig. 2B). However, when cells were cultured in M9 MM with citrate as the sole carbon source, the growth of $\triangle s d h C D A B$ was greatly compromised (Fig. 2C), suggesting that succinate dehydrogenase is, indeed, an anaplerotic enzyme essential for citrate metabolism in $D$. dadantii. In contrast, $\triangle$ fumA exhibited a similar growth rate and yield to the wild type in both LB and M9 MM supplemented with citrate (Fig. 2B and C). This might be attributed to the presence of two fumarase paralogues (fumB and fumC) in D. dadantii (Babujee et al. 2012).

\section{SdhCDAB and FumA are required}

to maintain the intracellular c-di-GMP level.

Although we observed that mutation of either fumA or $s d h C D A B$ led to the restoration of swimming motility in the $\Delta h f q$ mutant, it was still possible that these two genes control swimming motility in a c-di-GMP-independent manner. To determine whether SdhCDAB and FumA are bona fide regulators of c-diGMP, we measured the intracellular levels of c-di-GMP in the wild-type, $\Delta s d h C D A B, \Delta f u m A, \Delta h f q$, and $\Delta s d h C D A B \Delta h f q$ strains using ultraperformance liquid chromatography coupled with tandem mass spectrometry (UPLC-MS-MS). In accordance with the data from swimming motility assays (Fig. 2A), deletion of $s d h C D A B$ reduced the elevated c-di-GMP levels caused by $h f q$ (Fig. 3A). Additionally, significant reductions in c-di-GMP levels were also observed in single mutants of $s d h C D A B$ and fumA compared with the wild type (Fig. 3A). These data suggest that key enzymes in TCA cycle are essential for maintaining intracellular c-di-GMP in D. dadantii.

\section{Deletion of fumA and $s d h C D A B$ resulted in elevated Pel production.}

Pel is one of the major PCWDEs essential for bacterial virulence, and the production of Pel is negatively controlled by c-di-GMP in D. dadantii (Collmer and Keen 1986; Yi et al. 2010; Yuan et al. 2018). Because we observed a positive regulatory effect of SdhCDAB and FumA on c-di-GMP, we hypothesize that SdhCDAB and FumA may also negatively regulate Pel production in $D$. dadantii. As expected, a 1.6- and 1.3-fold increase in Pel production was observed in $\triangle s d h C D A B$ and $\triangle$ fumA, respectively, when compared with the wild type
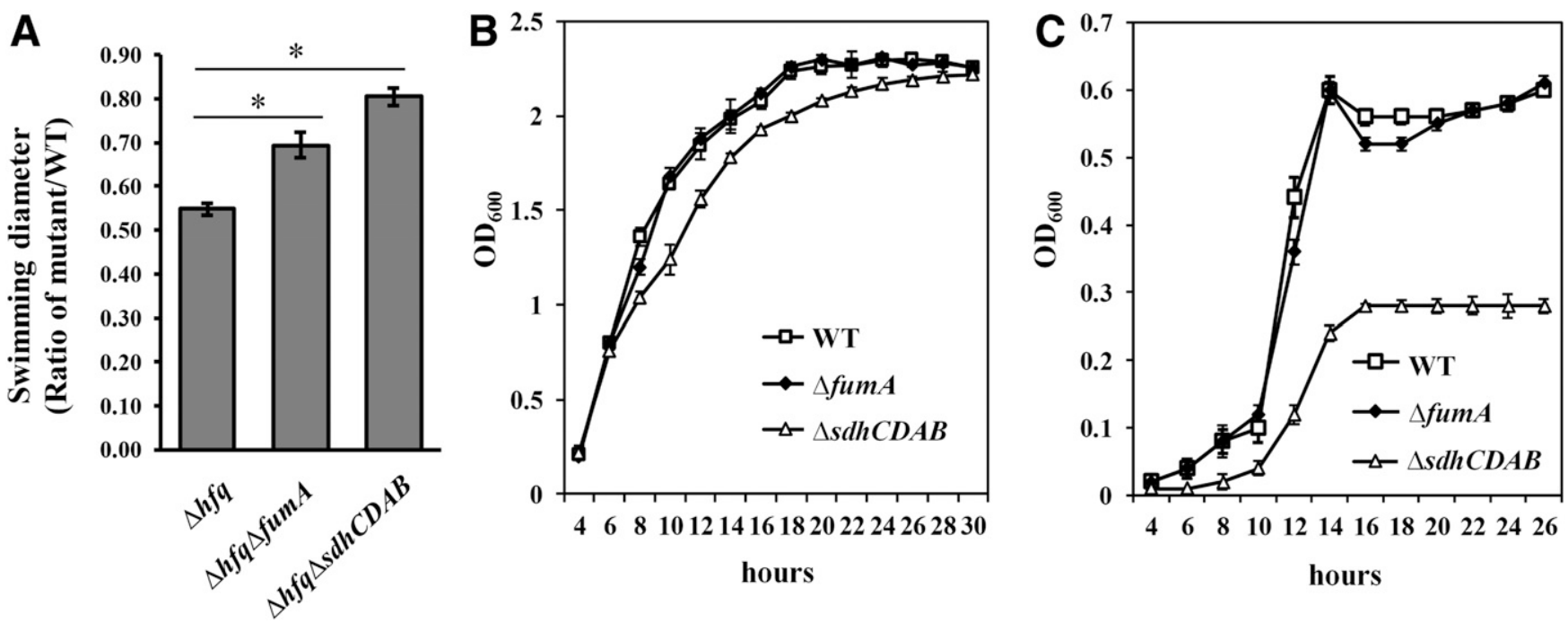

Fig. 2. Impact of fum $A$ and $s d h C D A B$ deletions on swimming motility and bacterial growth. A, Swimming motility was examined in wild-type (WT) bacteria and $\Delta h f q, \Delta h f q \Delta f u m A$, and $\Delta h f q \Delta s d h C D A B$ strains. The mutant/WT ratio for swimming diameter was calculated. Growth curves of WT Dickeya dadantii, $\triangle f u m A$, and $\triangle s d h C D A B$ were determined by measuring the optical density at $600 \mathrm{~nm}\left(\mathrm{OD}_{600}\right)$. Bacterial cells were cultured in $\mathbf{B}$, lysogeny broth medium or $\mathbf{C}$, M9 minimal medium supplemented with citrate as sole carbon source. Values are a representative of three independent experiments. Three replicates were used in each experiment. Error bars indicate standard errors of the means, ns represents nonsignificant, and asterisks indicate statistically significant differences of the means $(P<0.05$ by Student's $t$ test $)$. 
(Fig. 3B). The observed increase in both mutants could be fully restored to the wild-type level with an in trans complementation of the respective genes (Fig. 3B). The above results suggest that TCA enzymes SdhCDAB and FumA negatively control Pel production in $D$. dadantii.

\section{Impact of fumA and $s d h C D A B$ deletions on bacterial virulence in planta.}

During pathogenesis, D. dadantii acquires nutrients such as sugars and amino acids from plant tissues to support growth (Effantin et al. 2011; Lebeau et al. 2008), and the presence of the TCA cycle is necessary for energy generation (Jiang et al. 2016). Our findings, which showed that an imbalance in the TCA cycle strongly affected the production of the virulence determinant Pel, prompted us to investigate TCA cycle function in the pathogenesis of $D$. dadantii. We analyzed the impact of fumA and $s d h C D A B$ deletions on disease symptoms in different plants and plant tissues, including the leaves of Chinese cabbage (Brassica campestris) and potato tubers (Solanum tuberosum L.) (Fig. 4A and B). $\triangle$ fumA increased the maceration ability by approximately $20 \%$ relative to wild type in both plants, whereas the absence of a functional $s d h C D A B$ operon reduced the maceration ability by 75 and $20 \%$ in Chinese cabbage and potato tubers, respectively (Fig. 4A and B). Complementation experiments performed in both plant hosts showed that in trans expression of fumA or $s d h C D A B$ restored virulence to near wild-type levels (Fig. 4A and B).

\section{Addition of exogenous TCA intermediates divergently regulates Pel production.}

Although we documented a strong impact of the TCA enzymes SdhCDAB and FumA on c-di-GMP metabolism as well as the corresponding phenotypes controlled by c-di-GMP, it is not clear whether this regulation is mediated by the enzymes themselves or, rather, by some TCA metabolites that these enzymes catalyze. Because these enzymes convert one carboxylic acid to another, it is highly possible that the observed regulation is caused by the accumulation or reduction of certain substrates that these enzymes catalyze. Next, we investigated whether any of the TCA intermediates are involved in the SdhCDAB- or FumA-mediated regulation of c-di-GMP in $D$. dadantii by comparing the production of Pel in the presence of various exogenous carboxylic acids, including pyruvate, acetate, citrate, isocitrate, fumarate, and $\alpha$-ketoglutarate. Interestingly, twofold reductions on Pel production were observed with the addition of $0.4 \%$ pyruvate and acetate, and a sevenfold reduction was observed with the addition of $0.4 \%$ citrate (Fig. 4C). In contrast, isocitrate and fumarate increased Pel production and $\alpha$-ketoglutarate had no effect on Pel (Fig. 4C). Taken together, these data support our hypothesis that TCA intermediates affect Pel production in D. dadantii.

\section{Citrate-mediated repression on Pel is abolished in a $g c p A^{D 418 A}$ - and $r s m B$-overexpressing strain.}

To determine whether the regulation of Pel production by exogenous TCA intermediates is through the modulation of intracellular c-di-GMP, we compared the intracellular concentrations of c-di-GMP in the presence and absence of citrate, one of the representative TCA intermediates. Addition of $0.4 \%$ citrate increased the c-di-GMP concentration by 1.8 -fold, suggesting that citrate positively regulates c-di-GMP signaling (Fig. 5A). To further identify the c-di-GMP-producing DGCs responsive to the exogenous citrate, we compared the Pel production in the wild type and 12 GGDEF-domain-containing protein mutants (Yuan et al. 2018) in the presence and absence of exogenous citrate. Interestingly, addition of exogenous citrate caused significant reduction in the wild type, 10 putative
DGC mutants, and one confirmed DGC mutant $(\Delta g c p L)$ but did not affect the Pel production in $g c p A^{D 418 A}$ (a site-directed mutant that had lost the DGC activity of GcpA) (Yuan et al. 2018) (Fig. 5B). These observations suggest that the presence of a functional GcpA is essential for the citrate-mediated repression of Pel.

GcpA represses Pel by negatively regulating the expression of $r \sin B$, which encodes a small regulatory RNA (Yuan et al. 2018). If exogenous addition of citrate controls Pel through the GcpA-RsmB pathway, we would expect that the effect of citrate on Pel could be restored by overexpressing $r s m B$. Thus, we measured the Pel production of the wild type, wild-typeoverexpressing $r s m B$, and $\Delta r s m B$ in the presence and absence of $0.4 \%$ citrate. Adding $0.4 \%$ citrate caused a significant reduction in Pel production. However, the repressive effect was not observed in wild-type-/overexpressing $r \operatorname{smB}$ (Supplementary Fig. S1), suggesting that repression of Pel production by exogenous citrate is through the GcpA-RsmB pathway.

\section{Addition of citrate positively affects GcpA-mediated c-di-GMP signaling.}

To assess the molecular mechanism for the citrate-mediated regulation of c-di-GMP signaling via GcpA, we first examined the activity of citrate on Pel in a $g c p A^{D 418 A}$ complementation strain in which wild-type gcpA was expressed in trans from the low-copy-number plasmid pCL1920. In the absence of citrate, in trans expression of $g c p A$ repressed Pel production in $g c p A^{D 418 A}$ to wild-type levels, whereas the addition of citrate repressed Pel production approximately sevenfold relative to the wild type (Fig. 6A), indicating that the GcpA-mediated repression of $\mathrm{Pel}$ is enhanced by citrate supplementation. Because the DGC activity of GcpA is crucial for this regulation (Yuan et al. 2018) and our data demonstrated that addition of citrate increased the intracellular concentrations of c-di-GMP
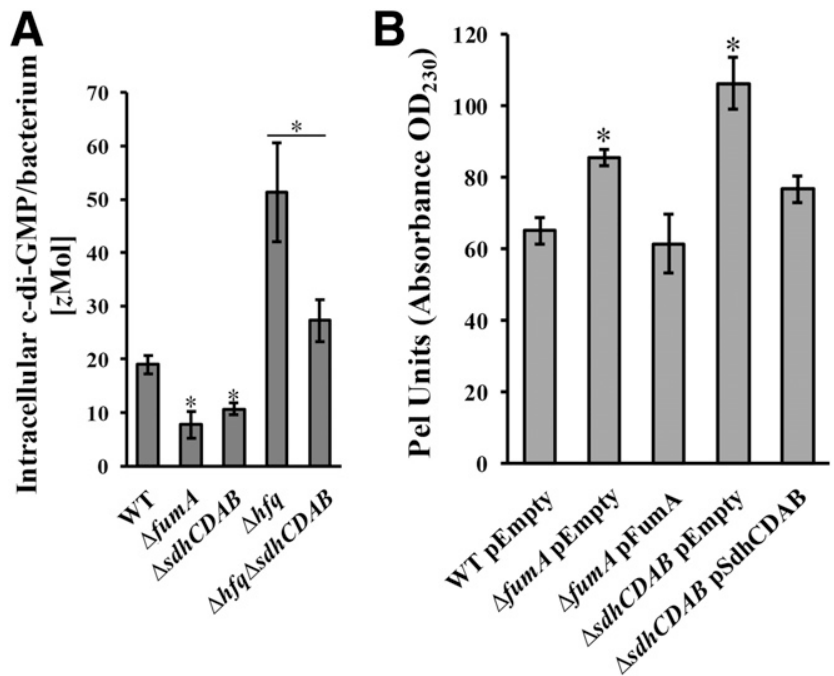

Fig. 3. Deletion of fumA and $s d h C D A B$ affects intracellular cyclic bis-( $3^{\prime}-$ $5^{\prime}$ )-cyclic dimeric guanosine monophosphate (c-di-GMP) and pectate lyase (Pel) production. A, Measurement of intracellular c-di-GMP in wild-type Dickeya dadantii, $\Delta f u m A, \Delta s d h C D A B, \Delta h f q$, and $\Delta h f q \Delta s d h C D A B$. Two independent experiments were performed, with three replicates in each experiment. Values are from one representative experiment. B, Pel production were measured in wild-type (WT) bacteria harboring pCL1920, $\triangle$ fumA harboring pCL1920, $\triangle$ fumA harboring pCL1920-fumA, $\triangle$ sdhCDAB harboring pCL1920, and $\triangle s d h C D A B$ pCL1920-sdhCDAB strains. $\mathrm{OD}_{230}=$ optical density at $230 \mathrm{~nm}$. Values are a representative of three independent experiments. Three replicates were used in the Pel production assay. Error bars indicate standard errors of the means and asterisks indicate statistically significant differences of the means compared with the wild-type $(P<0.05$ by Student's $t$ test). 
in wild-type $D$. dadantii (Fig. 5A), we hypothesized that the c-di-GMP levels of $g c p A^{D 418 A}$ (pGcpA) might be induced when citrate was supplemented. Indeed, a $27 \%$ increase of c-di-GMP levels was observed with the addition of $0.4 \%$ citrate compared with no added citrate (Fig. 6B).

\section{Addition of citrate does not enhance the dimerization of GcpA.}

The cyclase activity of DGC often requires dimerization because two GTP molecules need to be brought together by two GGDEF domains of two individual DGCs for catalysis during the biosynthesis of c-di-GMP (Schirmer and Jenal 2009). GcpA is predicted to be a cytoplasmic protein containing two types of N-terminal sensory domains-cGMP phosphodiesterase-adenyl cyclase-FhlA domain and Per/Arnt/Sim-and a C-terminal GGDEF domain (Supplementary Fig. S2) (Yuan et al. 2018). To determine whether addition of citrate affects the dimerization of GcpA, we integrated a bacterial two-hybrid (B2H) system to assess the physical interactions between GcpA proteins. A robust interaction was observed when $g c p A$ was cloned into both "bait" and "prey" vectors (p18GcpA-p25GcpA), whereas no interaction was observed for controls (p18GcpA-pKT25 and pUT18p25GcpA) (Fig. 6C), suggesting that GcpA can, indeed, form dimers in $D$. dadantii as observed in other bacteria (Schirmer and Jenal 2009). However, addition of citrate did not enhance the physical interaction between GcpA and GcpA (Fig. 6C), suggesting that the positive regulation of c-di-GMP by citrate is not through enhancing the dimerization of GcpA.

\section{Addition of citrate affects the protein levels} of GcpA and EGcpB.

To determine whether the citrate-mediated regulation of GcpA is via modulation of its production, we measured the protein levels of GcpA in the presence and absence of exogenous $0.4 \%$ citrate. Western blot analysis revealed an approximately $30 \%$ increase in GcpA protein levels when citrate was supplemented (Fig. 6D), suggesting that addition of citrate induces the production of GcpA in D. dadantii. In agreement with the Pel production data (Fig. 5B), citrate had no effect on the production of the other functional DGC, GcpL (Fig. 6D). EcpC and EGcpB are PDEs (Yi et al. 2010). However, only EGcpB is known to degrade the c-di-GMP produced by GcpA, because it positively controls Pel through the same regulatory pathway as GcpA (Yuan et al. 2018). Our data showed that the protein levels of EGcpB but not EcpC were reduced by $50 \%$ with the addition of citrate (Fig. 6D), confirming that a correlation between c-di-GMP signaling and TCA cycle does exist in D. dadantii. Supplementation of citrate, a TCA intermediate, induces the intracellular concentration of c-di-GMP by positively regulating the production of the DGC GcpA and negatively regulating the production of the PDE EGcpB.

\section{DISCUSSION}

In this study, we demonstrate a correlation between primary metabolism, the TCA cycle, and the secondary messenger c-diGMP in the plant pathogen $D$. dadantii. We first showed that disruption of the TCA cycle by mutating key anaplerotic enzymes $(\triangle s d h C D A B$ and $\triangle f u m A)$ caused repression of intracellular c-di-GMP and affected the corresponding c-diGMP-controlled phenotypes such as swimming motility and Pel production. Further investigation of the regulatory mechanism of these enzymes revealed that it is the TCA intermediates produced by these anaplerotic enzymes that played a role in the modulation of c-di-GMP and downstream phenotypes. Addition of exogenous citrate, one of the key TCA intermediates, induced the intracellular concentration of c-di-GMP and repressed the Pel-producing ability of $D$. dadantii. We further
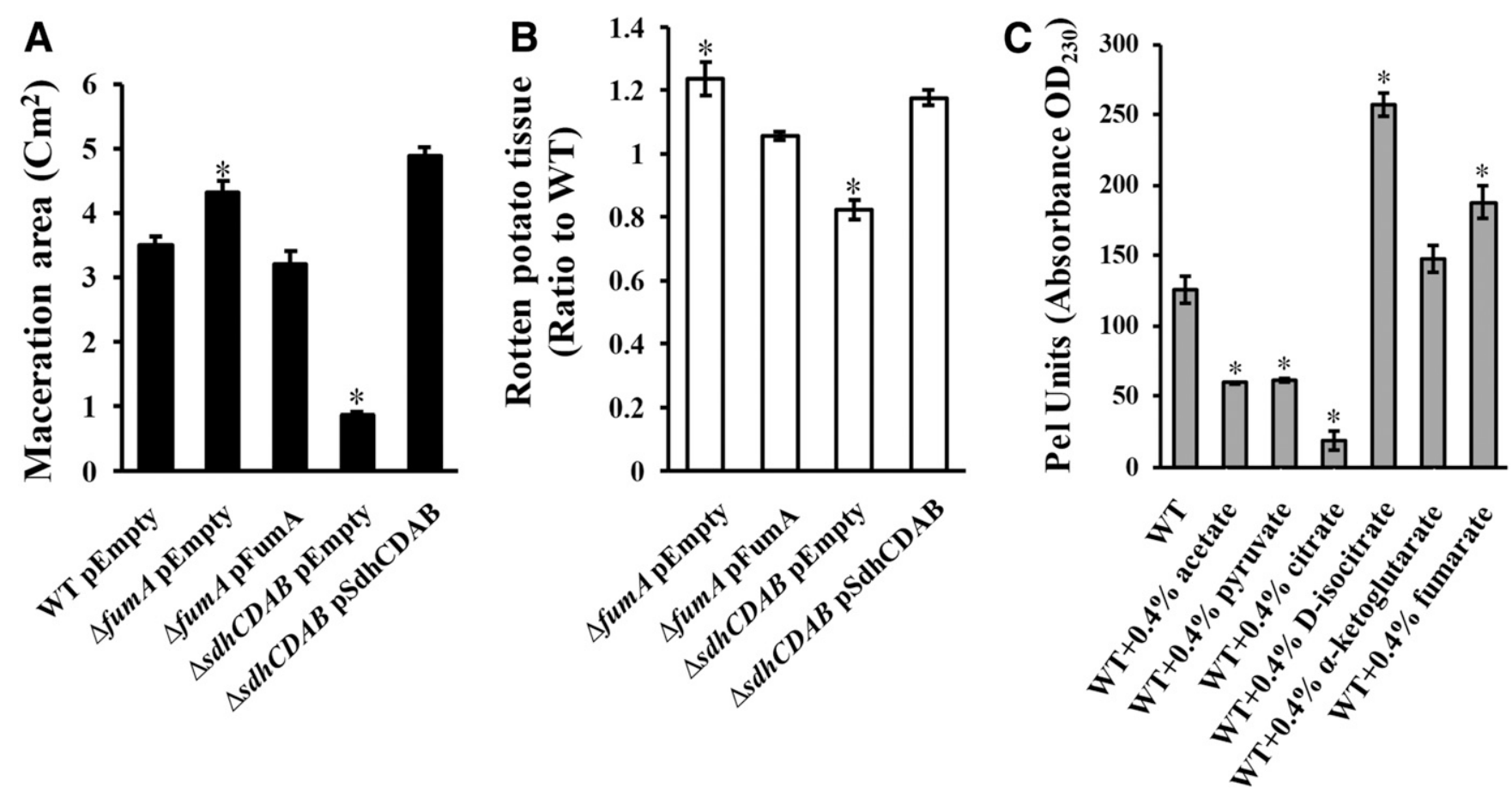

Fig. 4. Tricarboxylic acid (TCA) key enzyme deletions affect in planta virulence and impact of carboxylic acids on pectate lyase (Pel) production. A, Maceration on the leaves of Chinese cabbage and B, potato tubers were measured in wild-type (WT) bacteria harboring pCL1920, $\triangle$ fumA harboring pCL1920, $\Delta f u m A$ harboring pCL1920-fumA, $\triangle s d h C D A B$ harboring pCL1920, and $\triangle s d h C D A B$ pCL1920-sdhCDAB strains. Three independent experiments were performed. Five leaves of Chinese cabbage and three potato tubers were used for each strain. Values are from one representative experiment. C, Pel production was measured in WT Dickeya dadantii and D. dadantii supplemented with $0.4 \%(\mathrm{wt} / \mathrm{vol})$ various carboxylic acids. $\mathrm{OD}_{230}=$ optical density at $230 \mathrm{~nm}$. Experiments were repeated three times with three replicates. Error bars indicate standard errors of the means and asterisks indicate statistically significant differences of the means $(P<0.05$ by Student's $t$ test). 
revealed that addition of exogenous citrate caused an increased production of a DGC (GcpA) and decreased production of a PDE (EGcpB). Thus, findings from this study depict a novel regulatory cascade of how TCA enzyme activity or the levels of TCA intermediates may provide a signal for the c-di-GMP signaling and virulence modulation in bacteria (Fig. 7).

The TCA cycle is a respiration metabolism that is required for bacterial growth under aerobic conditions. Interestingly, TCA enzymes or intermediates have also been shown to control a great variety of cellular processes, including pathogenicity. In Pseudomonas aeruginosa, mutations of the TCA cycle enzymes greatly affect the expression of T3SS genes (Dacheux et al. 2002; Rietsch and Mekalanos 2006). Further study in $P$. fluorescens showed that deletion of $p y c A B$ genes (encoding pyruvate carboxylase) or fumA divergently affected the expression of three RsmA-associated sRNAs (RsmX, -Y, and -Z), thus affecting RsmA-dependent cellular activities (Takeuchi et al. 2009). D. dadantii encodes only one RsmA-antagonistic sRNA, RsmB, and the RsmA/B system has been shown to regulate several virulence factors, including Pel and T3SS (Yang et al. 2008). Because c-di-GMP posttranscriptionally represses $r s m B$ expression (Yuan et al. 2018), our observation that an impaired TCA cycle resulted in low c-di-GMP levels strongly indicates that the TCA cycle-mediated regulation of Pel could be regulated through RsmB. It also suggests that the regulation of the TCA cycle on the expression of RsmAassociated sRNAs is common in different bacterial species.

Because the regulation of the TCA cycle is mainly governed by substrate availability and allosteric regulation, knowing which TCA enzymes or intermediates are responsible for controlling c-di-GMP is difficult. This is also supported by our observation that addition of various carboxylic acids, including pyruvate, acetate, citrate, isocitrate, fumarate, and $\alpha$-ketoglutarate, exhibited different phenotypes on Pel production. Citrate derived from acetyl-CoA can be generated via the acetate catabolic pathway or oxidative decarboxylation of pyruvate (Fig. 7), suggesting that the repressive impact on Pel from the addition of acetate and pyruvate could be the result of citrate. On the other hand, it remains to be determined whether the positive impact on Pel from isocitrate and fumarate is a direct regulation or an indirect negative feedback on citrate availability.

A recent study in $P$. fluorescens reported that exogenous citrate binds to the calcium channel chemotaxis receptor (CACHE) domain of GcbC to stimulate its DGC activity for controlling biofilm formation (Giacalone et al. 2018). In D. dadantii, we observed a similar phenotype, because the addition of citrate increased the intracellular concentration of c-di-GMP (Fig. 5A), whereas deletion of the $s d h C D A B$ operon resulted in an imbalance in the TCA cycle and decreased c-diGMP levels (Fig. 3A). It is intriguing that D. dadantii has two GGDEF domain proteins, GcpL and GcpG, which both contain an annotated N-terminal CACHE domain. The functional role of GcpL has been recently explored (Yuan et al. 2019) but not for GcpG. Amino acid sequence alignment of the CACHE domains showed that three arginine residues for binding between citrate and GcbC are not present in either GcpL or GcpG (Supplementary Fig. S3), suggesting that citrate might not act as a direct ligand for these two enzymes in $D$. dadantii. Our results from Pel production support this hypothesis, showing that deletion of either of $g c p L$ or $g c p G$ had no impact on the citrate-mediated repression on Pel (Fig. 5B).

A unique feature for c-di-GMP signaling that differs from other well-studied secondary messengers such as cyclic $3^{\prime}-5^{\prime}$ adenosine phosphate and guanosine-(penta)tetraphosphate is the large number of genes encoding c-di-GMP-metabolic enzymes in bacterial genomes (Hengge et al. 2015). This poses an interesting question: why do bacteria need so many of these enzymes if they are functionally redundant? An increasing body of research has uncovered various environmental and
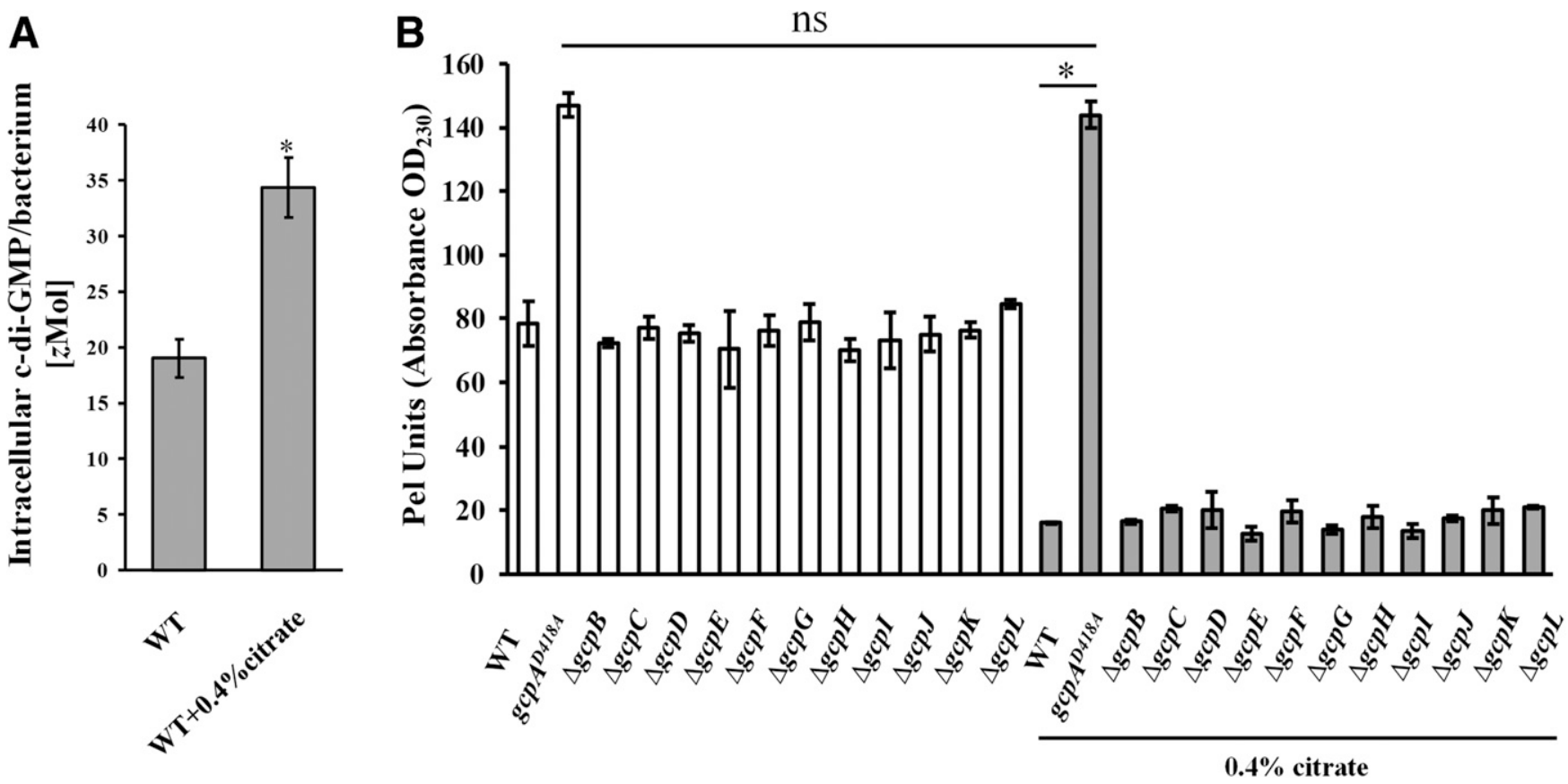

Fig. 5. Addition of citrate affects intracellular concentrations of cyclic bis- $\left(3^{\prime}-5^{\prime}\right)$-cyclic dimeric guanosine monophosphate (c-di-GMP) and pectate lyase (Pel) production. A, Intracellular concentrations of c-di-GMP were determined in wild-type (WT) Dickeya dadantii with and without the addition of $0.4 \%$ (wt/vol) sodium citrate. Experiments were performed two times with three replicates. B, Pel production was measured in WT $D$. dadantii, $g c p A^{D 418 A}, \Delta g c p B, \Delta g c p C$, $\Delta g c p D, \Delta g c p E, \Delta g c p F, \Delta g c p G, \Delta g c p H, \Delta g c p I, \Delta g c p J, \Delta g c p K$, and $\Delta g c p L$ strains in the absence of sodium citrate (white bar) and in the addition of $0.4 \%$ $\left(\mathrm{wt} / \mathrm{vol}\right.$ ) sodium citrate (gray bar). $\mathrm{OD}_{230}=$ optical density at $230 \mathrm{~nm}$. One representative experiment was chosen, and three independent experiments with three replicates were performed. Error bars indicate standard errors of the means and asterisks indicate statistically significant differences of the means (ns $=$ not significant, $P>0.05 ; P<0.05$ by Student's $t$ test) 
intracellular signals that trigger c-di-GMP metabolism, thus favoring a specific c-di-GMP signaling model (Giacalone et al. 2018; Hengge et al. 2015; Townsley and Yildiz 2015; Tuckerman et al. 2009). Our findings provide an important connection between the TCA cycle enzymes or intermediates and c-diGMP metabolism. We find that addition of citrate induced the production of GcpA while repressing the production of EGcpB. This is particularly interesting because we recently found that GcpA and EGcpB control Pel via regulating the same c-diGMP pool (Yuan et al. 2018). It is also in agreement with our hypothesis that citrate does not appear to act as a direct ligand for the c-di-GMP metabolic enzymes in $D$. dadantii. Nevertheless, TCA cycle intermediates and enzymes play essential roles in controlling cellular behaviors and virulence factors in bacteria, including Escherichia coli, P. aeruginosa, P. fluorescens, Staphylococcus aureus, and Agrobacterium tumefaciens (Ding et al. 2014; Kuo et al. 2018; Suksomtip et al. 2005; Takeuchi et al. 2009). For example, fumarate modulates flagellar rotation via targeting a fumarate reductase that binds to flagellar switch component FliG (Cohen-Ben-Lulu et al. 2008). Deletion of

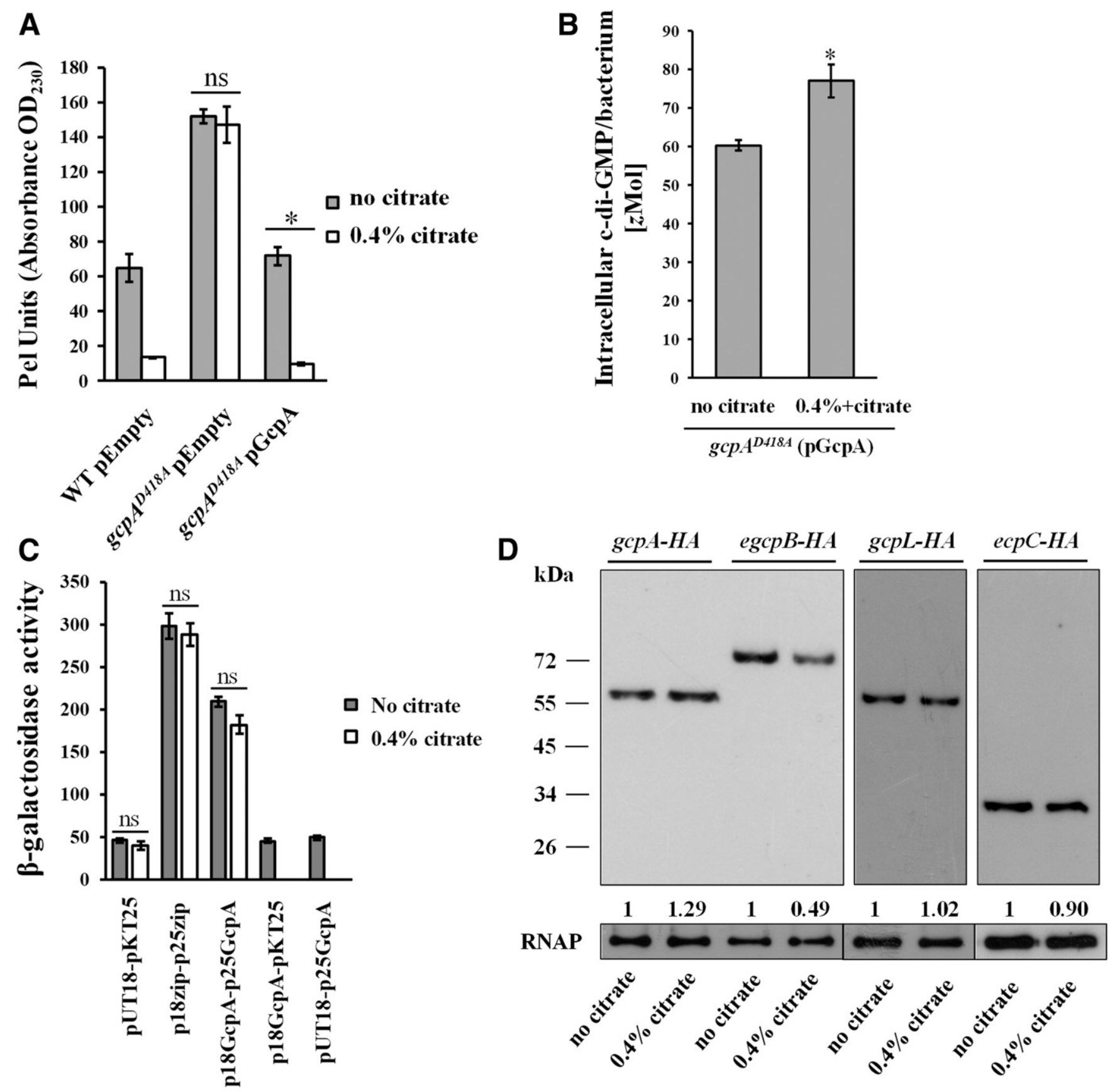

Fig. 6. Pleiotropic effects of addition of citrate on GcpA-related phenotypes. A, Pectate lyase (Pel) production was determined for wild-type (WT) Dickeya dadantii harboring pCL1920, gcpA ${ }^{D 418 A}$ harboring pCL1920, and $g c p A^{D 418 A}$ harboring pCL1920-gcpA with or without the supplementation of $0.4 \%$ (wt/vol) sodium citrate. $\mathrm{OD}_{230}=$ optical density at $230 \mathrm{~nm}$. B, Intracellular cyclic bis-( $\left.3^{\prime}-5^{\prime}\right)$-cyclic dimeric guanosine monophosphate (c-di-GMP) of $g c p A^{D 418 A}$ harboring pCL1920-gcpA with or without the supplementation of $0.4 \%(\mathrm{wt} / \mathrm{vol})$ sodium citrate. Two independent experiments with three replicates were performed. $\mathbf{C}, \beta$-Galactosidase activity representing the extent of GcpA's dimerization was measured relative to controls with and without the addition of $0.4 \%$ $(\mathrm{wt} / \mathrm{vol})$ sodium citrate. Experiments were repeated three times independently with similar results. Three replicates were used for each experiment. Error bars indicate standard errors of the means. D, Western blot analysis was performed to detect GcpA-HA, GcpL-HA, EcpC-HA and EGcpB-HA. Three independent experiments were performed; a representative blot is shown. Asterisks indicate statistically significant differences of the means $(P<0.05$ by Student's $t$ test); ns $=$ not significant. 
ace $A B$, encoding pyruvate dehydrogenase that converts pyruvate to acetyl-CoA, strongly attenuates T3SS of $P$. aeruginosa and is nonvirulent in a rat model (Dacheux et al. 2002). In D. dadantii, further experiments are planned to elucidate the detailed regulatory mechanism of the TCA cycle on c-di-GMP metabolism.

Finally, an intriguing question is why $D$. dadantii would use intracellular TCA intermediates to modulate virulence phenotype. During spread and infection, $D$. dadantii would encounter aerobic and anaerobic stages of life styles (Reverchon and Nasser 2013). Because the TCA cycle is only active during aerobic respiration but not during anaerobic respiration, it is possible that the TCA intermediates would serve as a signal for the transition between aerobic and anaerobic infection states. It is known that $D$. dadantii encounters low oxygen availability in the plant apoplast, which positively contributes to the production of Pels and soft rot disease symptoms (HugouvieuxCotte-Pattat et al. 1992; Reverchon and Nasser 2013). When oxygen and nutrients are available, a functional TCA cycle may help the pathogen to maximize growth. However, under nutrient-limited or low-oxygen condition such as in the plant apoplast, $D$. dadantii starts to transition from aerobic respiration to anaenrobic respiration, and the reduced TCA activity would then be used as signal to turn on the expression of virulence factors, an energy-consuming process, via c-di-GMP signaling for a successful secondary infection. This hypothesis is also in line with the notion from other pathogenic bacteria that vegetative growth and virulence expression represent two distinct life styles (Cui et al. 2019; Leggett et al. 2017; Meyer et al. 2010). On the other hand, because citrate is a small molecule that is permeable through cellular membranes, $D$. dadantii can also obtain host-derived metabolites such as citrate to support vegetative growth. In another Enterobacteriaceae soft-rot pathogen, Pectobacterium atrosepticum, inactivation of the citrate transporter leads to reduced virulence in potato tubers (Urbany and Neuhaus 2008). A similar observation has also been reported in Xanthomonas campestris pv. vesicatoria, the causal agent of bacterial leaf spot on pepper and tomato (Tamir-Ariel et al. 2007), suggesting that citrate uptake and metabolism is required for bacterial virulence in planta. Indeed, we observe that deletion of $\operatorname{sdh} C D A B$ in $D$. dadantii resulted in a compromised TCA cycle and reduced virulence phenotype in the leaves of Chinese cabbage and potato tubers, despite the fact that both the swimming motility and Pel were upregulated under the laboratory conditions. Because citrate can derive from either the host or bacteria, future

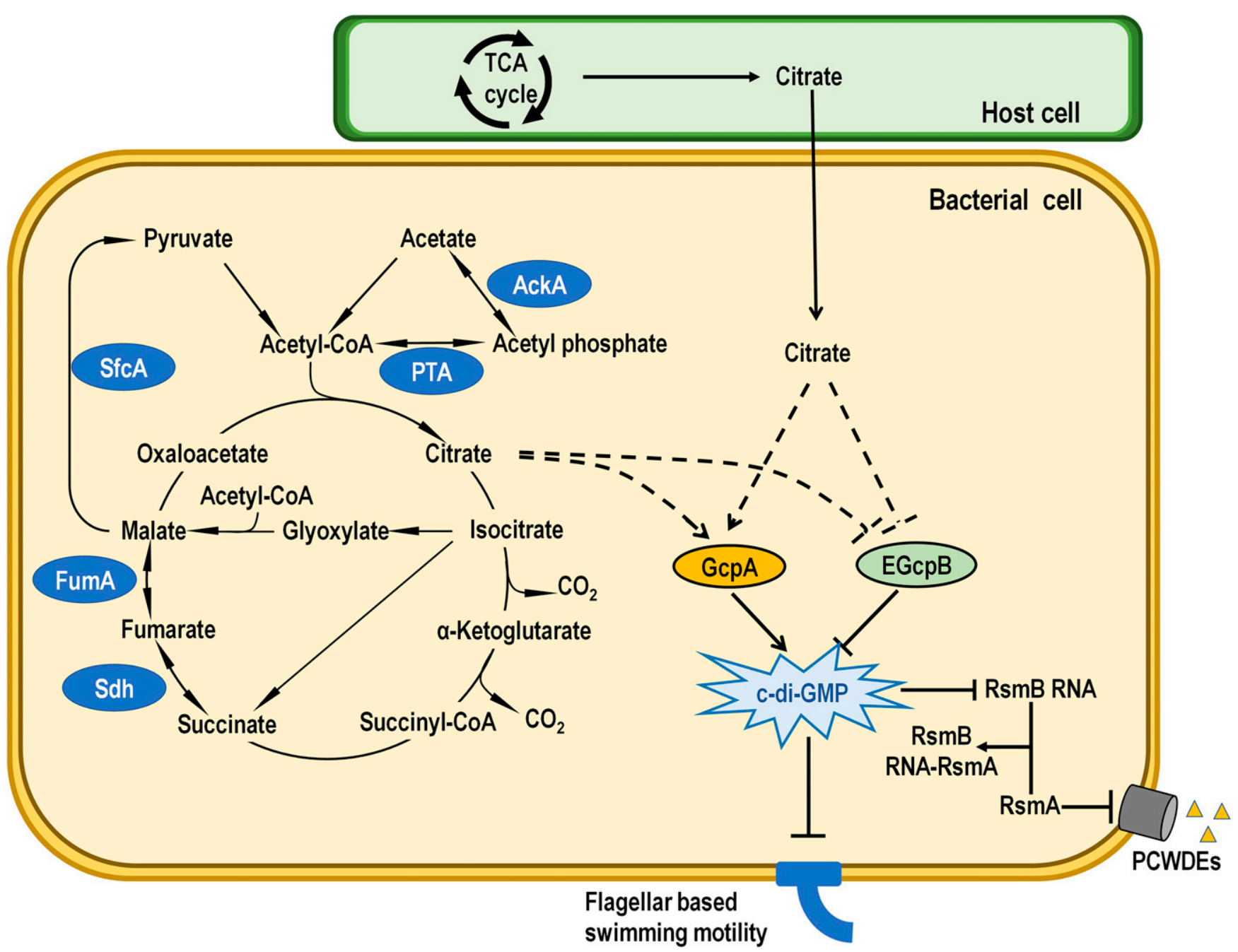

Fig. 7. Model of tricarboxylic acid (TCA) cycle-mediated regulatory mechanism on swimming and pectate lyase (Pel) via cyclic bis-( $\left.3^{\prime}-5^{\prime}\right)$-cyclic dimeric guanosine monophosphate (c-di-GMP) signaling in Dickeya dadantii. TCA cycle enzymes or intermediates modulate the intracellular concentrations of c-diGMP by upregulating the production of a diguanylate cyclase (GcpA) whereas downregulating the production of a phosphodiesterase (EGcpB). GcpA and EGcpB control the same c-di-GMP pool that represses swimming motility and negatively regulates Pel production through RsmB. sRNA RsmB binds to RsmA, a global posttranscriptional regulator, that titrates RsmA activity. RsmA negatively controls Pel in $D$. dadantii. Symbols: $\perp$ represents the negative control, $\rightarrow$ represents the positive control, and dotted lines indicate regulatory mechanisms identified in this study. PCWDEs $=$ plant cell wall-degrading. 
research is needed to understand how the host-derived and pathogen-derived citrate interplay to regulate c-di-GMP and Pel production during the host-pathogen interactions.

\section{MATERIALS AND METHODS}

\section{Strains, plasmids, primers, and media.}

The bacterial strains and plasmids used in this study are listed in Table 1. D. dadantii strains were grown in LB medium (tryptone at $10 \mathrm{~g} /$ liter, yeast extract at $5 \mathrm{~g} / \mathrm{liter}$, and $\mathrm{NaCl}$ at $10 \mathrm{~g} /$ liter), mannitol-glutamic acid (MG) medium (mannitol at $10 \mathrm{~g} /$ liter, glutamic acid at $2 \mathrm{~g} /$ liter, potassium phosphate monobasic at $0.5 \mathrm{~g} /$ liter, $\mathrm{NaCl}$ at $0.2 \mathrm{~g} /$ liter, and $\mathrm{MgSO}_{4}$ at $0.2 \mathrm{~g} /$ /iter) or M9 MM supplemented with citrate as sole carbon source $\left(\mathrm{Na}_{2} \mathrm{HPO}_{4}\right.$ at $6 \mathrm{~g} /$ liter, $\mathrm{KH}_{2} \mathrm{PO}_{4}$ at $3 \mathrm{~g} /$ liter, $\mathrm{NH}_{4} \mathrm{Cl}$ at $1 \mathrm{~g} /$ liter, $\mathrm{NaCl}$ at $0.5 \mathrm{~g} /$ liter, $1 \mathrm{mM} \mathrm{MgSO}_{4}, 0.1 \mathrm{mM}$ $\mathrm{CaCl}_{2}$, and $0.2 \%$ [wt/vol] sodium citrate) at $28^{\circ} \mathrm{C}$. E. coli strains were grown in LB medium at $37^{\circ} \mathrm{C}$. Antibiotics were added to the media at the following concentrations: kanamycin $(\mathrm{Km})(50 \mu \mathrm{g} / \mathrm{ml})$ and spectinomycin $(100 \mu \mathrm{g} / \mathrm{ml})$. The D. dadantii 3937 genome sequence can be retrieved from a systematic annotation package for community analysis of genomes (ASAP; University of Wisconsin). Primers used for cloning are listed in Table 2.

\section{Swimming motility assay.}

A swimming motility assay was performed as previously described (Antúnez-Lamas et al. 2009). Briefly, bacterial cells were cultured overnight in LB broth at $28^{\circ} \mathrm{C}$ and the optical density at $600 \mathrm{~nm}\left(\mathrm{OD}_{600}\right)$ values were adjusted to 1.0. Bacterial cultures $(10 \mu \mathrm{l}$ each) were inoculated onto the center of MG plates containing $0.2 \%$ agar. The diameter of the radial growth was measured after $16 \mathrm{~h}$ of incubation at $28^{\circ} \mathrm{C}$.

\section{Transposon mutagenesis.}

Mutagenesis was performed by conjugating the $h f q$ unmarked mutant strain with $E$. coli S17-1 $\lambda$-pir containing transposon miniHimar RB1 (Bouhenni et al. 2005). Conjugates were plated onto $\mathrm{MG}$ agar plates containing $\mathrm{Km}$ and incubated for 2 days at $28^{\circ} \mathrm{C}$. Transposon mutants were then picked and inoculated into LB broth and cultured for the swimming motility assay. Mutants that showed an enhanced swimming zone compared with the $h f q$ deletion mutant were preserved. A previously described method was used to identify the transposon insertion sites, with few modifications (Bouhenni et al. 2005). In brief, genomic DNA of transposon mutants was purified using the phenol-chloroform method (Sambrook and Russell 2006). Purified DNA was then digested by BamHI restriction enzyme and self ligated. Ligation products were

Table 1. Bacterial strains and plasmids used in this study and their relevant characteristics

\begin{tabular}{|c|c|c|}
\hline Strains and plasmids & Relevant characteristics $^{\mathbf{a}}$ & Reference or source \\
\hline \multicolumn{3}{|l|}{ Dickeya dadantii } \\
\hline 3937 & Wild type & N. Hugouvieux-Cotte-Pattat \\
\hline$\Delta h f q$ & $\Delta h f q$; clean mutant, ABF-0015209 deletion mutant & Yuan et al. 2019 \\
\hline$\triangle$ fumA & $\Delta$ fumA $:: K m ; \mathrm{Km}^{\mathrm{r}}, \mathrm{ABF}-0016800$ deletion mutant & This study \\
\hline$\triangle s d h C D A B$ & $\begin{array}{l}\Delta s d h C D A B:: K m ; \mathrm{Km}^{\mathrm{r}}, \mathrm{ABF}-0016957, \mathrm{ABF}-0016956, \mathrm{ABF}-0016955, \text { and } \\
\text { ABF-0016953 deletion mutant }\end{array}$ & This study \\
\hline$\Delta h f q \Delta f u m A$ & $\Delta h f q \Delta f u m A:: K m ; \mathrm{Km}^{\mathrm{r}}$ & This study \\
\hline$\Delta h f q \Delta s d h C D A B$ & $\Delta h f q \Delta s d h C D A B:: K m ; \mathrm{Km}^{\mathrm{r}}$ & This study \\
\hline$g c p A^{D 418 A}$ & $\operatorname{gcpA}^{D 418 A}:: \mathrm{Km} ; \mathrm{Km}^{\mathrm{r}}, \mathrm{ABF}-0020368$ site-directed mutant & Yuan et al. 2018 \\
\hline$\triangle g c p B$ & $\Delta g c p B:: K m ; \mathrm{Km}^{\mathrm{r}}, \mathrm{ABF}-0016029$ deletion mutant & Yi et al. 2010 \\
\hline$\triangle g c p C$ & $\Delta g c p C:: K m ; \mathrm{Km}^{\mathrm{r}}, \mathrm{ABF}-0019499$ deletion mutant & Yi et al. 2010 \\
\hline$\triangle g c p D$ & $\Delta g c p D:: K m ; \mathrm{Km}^{\mathrm{r}}, \mathrm{ABF}-0014719$ deletion mutant & Yi et al. 2010 \\
\hline$\triangle g c p E$ & $\Delta g c p E:: K m ; \mathrm{Km}^{\mathrm{r}}$, ABF-0019019 deletion mutant & Yuan et al. 2018 \\
\hline$\triangle g c p F$ & $\Delta g c p F:: K m ; \mathrm{Km}^{\mathrm{r}}, \mathrm{ABF}-0016283$ deletion mutant & Yi et al. 2010 \\
\hline$\triangle g c p G$ & $\Delta g c p G:: K m ; \mathrm{Km}^{\mathrm{r}}, \mathrm{ABF}-0019796$ deletion mutant & Yuan et al. 2018 \\
\hline$\triangle g c p H$ & $\Delta g c p H:: K m ; \mathrm{Km}^{\mathrm{r}}, \mathrm{ABF}-0015146$ deletion mutant & Yuan et al. 2018 \\
\hline$\Delta g c p I$ & $\Delta g c p I:: K m ; \mathrm{Km}^{\mathrm{r}}, \mathrm{ABF}-0017509$ deletion mutant & Yuan et al. 2018 \\
\hline$\triangle g c p J$ & $\Delta g c p J:: K m ; \mathrm{Km}^{\mathrm{r}}, \mathrm{ABF}-0019128$ deletion mutant & Yuan et al. 2018 \\
\hline$\triangle g c p K$ & $\Delta g c p K:: K m ; \mathrm{Km}^{\mathrm{r}}, \mathrm{ABF}-0019798$ deletion mutant & Yuan et al. 2018 \\
\hline$\triangle g c p L$ & $\Delta g c p L:: K m ; \mathrm{Km}^{\mathrm{r}}, \mathrm{ABF}-0015843$ deletion mutant & Yuan et al. 2018 \\
\hline$\Delta r s m B$ & $\Delta r s m B:: K m ; \mathrm{Km}^{\mathrm{r}}, \mathrm{ABF}-0061322$ deletion mutant & Yuan et al. 2018 \\
\hline gсрA-HA & Chromosomal gcpA-HA; ABF-0020368 & Yuan et al. 2019 \\
\hline еgсрB-HA & Chromosomal egcpB-HA; ABF-0020123 & Yuan et al. 2019 \\
\hline ecpC-HA & Chromosomal ecpC-HA; ABF-0020364 & Yuan et al. 2019 \\
\hline gcpL-HA & Chromosomal gcpL-HA; ABF-0015843 & Yuan et al. 2019 \\
\hline \multicolumn{3}{|l|}{ Escherichia coli } \\
\hline DH5 $\alpha$ & supE44 $\Delta l a c \mathrm{U} 169$ ( $\phi 80$ lacZAM15) hsdR17 recA1 endA1 gyrA96 thi-1 relA1 & Lab stock \\
\hline S17-1 $\lambda$ pir & $\lambda$ (pir) $h s d R$ pro thi; chromosomally integrated RP4-2 Tc::Mu Km::Tn7 & Lab stock \\
\hline BTH101 & Reporter strain for bacterial two-hybrid assay & Euromedex \\
\hline \multicolumn{3}{|c|}{ te } \\
\hline pKD4 & Template plasmid for kanamycin cassette, $\mathrm{Km}^{\mathrm{r}}$ & Datsenko and Wanner 2000 \\
\hline pWM91 & Sucrose-based counter-selectable plasmid, Ap ${ }^{r}$ & Metcalf et al. 1996 \\
\hline pCL1920 & Low-copy-number plasmid, lac promoter, $\mathrm{Sp}^{\mathrm{r}}$ & Lerner and Inouye 1990 \\
\hline p1920-fumA & fumA cloned in $\mathrm{pCL} 1920, \mathrm{Sp}^{\mathrm{r}}$ & This study \\
\hline p1920-sdhCDAB & $s d h C D A B$ cloned in $\mathrm{pCL} 1920, \mathrm{Sp}^{\mathrm{r}}$ & This study \\
\hline p1920-rsmB & $r s m B$ cloned in pCL1920, $\mathrm{Sp}^{\mathrm{r}}$ & Yuan et al. 2015 \\
\hline p1920-gcpA & gcpA cloned in pCL1920, $\mathrm{Sp}^{\mathrm{r}}$ & Yuan et al. 2018 \\
\hline pKT25 & Bacterial two-hybrid vector & Euromedex \\
\hline pUT18 & Bacterial two-hybrid vector & Euromedex \\
\hline pKT25-zip & Bacterial two-hybrid positive control & Euromedex \\
\hline pUT18-zip & Bacterial two-hybrid positive control & Euromedex \\
\hline pKT25-gсрA & pKT25 containing gcpA & This study \\
\hline pUT18-gсрA & pUT18 containing gcpA & This study \\
\hline
\end{tabular}

${ }^{\mathrm{a}} \mathrm{Km}^{\mathrm{r}}, \mathrm{Ap}^{\mathrm{r}}$, and $\mathrm{Sp}^{\mathrm{r}}$ indicate kanamycin, ampicillin, and spectinomycin resistance, respectively. 
transferred into $E$. coli $\mathrm{DH} 5 \alpha \lambda$-pir competent cells and plated onto LB agar containing $\mathrm{Km}$. Colonies were then picked and cultured. Self-ligated DNA containing transposon was purified and sequenced using primers 615 and Himar1 (Table 2).

\section{Mutant construction and complementation.}

The fumA gene and $s d h C D A B$ operon were deleted from the genome by allelic exchange mutagenesis (Yang et al. 2002). Two flanking regions upstream and downstream of each target gene were amplified by PCR using specific primers (Table 2 ). The Km cassette was amplified from pKD4 plasmid (Datsenko and Wanner 2000) and cloned between two flanking regions using three-way crossover PCR. The PCR construct was purified, digested by XhoI and NotI restriction enzymes, and inserted into a suicide plasmid (pWM91). The resulting plasmid was transformed into $E$. coli strain S17-1 $\lambda$-pir, which was then conjugated with $D$. dadantii. Recombinants that recovered on $\mathrm{Km}$ medium were plated on a $10 \%$ sucrose plate for selection of cells with chromosomal deletions. Sucrose resistance cells due to the loss of SacB-mediated toxicity were plated on an ampicillin plate, and the ampicillin-sensitive cells were confirmed by PCR using outside primers. Mutations were further confirmed by sequencing. To generate double mutants, fumA and $s d h C D A B$ were allelic exchanged in an $h f q$ unmarked mutant strain that was previously constructed (Yuan et al. 2019).

To generate complemented or overexpression strains, the putative promoter and ORF regions of target genes were amplified and cloned into a low-copy-number plasmid, pCL1920 (Table 1). The resulting plasmids were then confirmed by sequencing and electroporated into $D$. dadantii cells.

\section{Pel production assay.}

Extracellular Pel activity was measured by spectrometry as previously described (Matsumoto et al. 2003). In brief, bacterial cells were cultured in LB broth supplemented with $0.1 \%$ (wt/vol) polygalacturonic acid (PGA) at $28^{\circ} \mathrm{C}$ for $16 \mathrm{~h}$. When needed, $0.4 \%(\mathrm{wt} / \mathrm{vol})$ sodium citrate, sodium pyruvate, sodium acetate, sodium fumarate dibasic, $\alpha$-ketoglutaric acid disodium salt dihydrate, or DL-isocitric acid trisodium salt hydrate (SigmaAldrich, St. Louis, MO, U.S.A.) were applied. The $\mathrm{OD}_{600}$ of bacterial cultures was measured and normalized. Culture supernatant was collected by centrifugation of $1 \mathrm{ml}$ of bacterial cultures at $13,000 \times g$ for $2 \mathrm{~min}$. The supernatant $(10 \mu \mathrm{l})$ was added into $990 \mu \mathrm{l}$ of the reaction buffer $(0.05 \%$ [wt/vol] PGA, $0.1 \mathrm{M}$ Tris- $\mathrm{HCl}[\mathrm{pH} 8.5]$, and $0.1 \mathrm{mM} \mathrm{CaCl}$, prewarmed to $30^{\circ} \mathrm{C}$ ). Pel activity was monitored at an absorbance at $230 \mathrm{~nm}$ for 3 min and calculated based on one unit of Pel activity being equal to an increase of $1 \times 10^{-3} \mathrm{OD}_{230}$ in $1 \mathrm{~min}$.

\section{Measurement of the intracellular c-di-GMP concentration.}

To determine the intracellular concentrations of c-di-GMP, UPLC-MS-MS was used as previously described (Massie et al. 2012). Overnight bacterial cultures were inoculated 1:100 into $15 \mathrm{ml}$ of LB medium with or without the addition of $0.4 \%$ (wt/vol) sodium citrate and incubated at $28^{\circ} \mathrm{C}$ until the $\mathrm{OD}_{600}$ reached approximately 0.8 , which corresponded to the mid- to late-exponential growth phase. Meanwhile, cell number was determined by plate counting. Bacterial cells were harvested by centrifugation at $1,500 \times$ $g$ for $30 \mathrm{~min}$. Cell pellets were then resuspended in $1.5 \mathrm{ml}$ of extraction buffer $(40 \%$ [ $\mathrm{vol} / \mathrm{vol}]$ acetonitrile and $40 \%$ [vol $/ \mathrm{vol}]$ methanol in $0.1 \mathrm{~N}$ formic acid) and incubated at $-20^{\circ} \mathrm{C}$ for 30 $\mathrm{min}$. After centrifugation for $5 \mathrm{~min}$ at $21,000 \times g$ to pellet insoluble debris, the supernatant containing c-di-GMP was collected and dried using a speed-vac. c-di-GMP was resuspended in $100 \mu \mathrm{l}$ of high-performance liquid chromatography-grade water, filtered through a Titan syringe filter (polyvinylidene difluoride, $0.45 \mu \mathrm{m}$, $4 \mathrm{~mm}$ ), and analyzed by UPLC-MS-MS. Intracellular concentration of c-di-GMP was calculated per cell.

\section{Western blot analysis.}

To measure the protein levels of GcpA, GcpL, EcpC, and $\mathrm{EGcpB}$, previously constructed strains in which the wild-type gene was allelic exchanged to a hemagglutinin (HA)-tagged version were used (Yuan et al. 2019). Western blot was performed using D. dadantii cells containing HA that were grown in LB broth with or without the supplementation of $0.4 \%$ (wt/vol) sodium citrate for $16 \mathrm{~h}$ at $28^{\circ} \mathrm{C}$. Cells were collected by centrifugation, resuspended in phosphate-buffered saline (PBS) buffer, and lysed by sonication. The protein in crude lysates was quantified using the Bradford protein assay (Bio-Rad, Hercules, CA, U.S.A.). The same amount of protein samples was boiled and loaded onto $12 \%$ sodium dodecyl sulfate polyacrylamide gel electrophoresis gels. Proteins were separated at $120 \mathrm{~V}$ constant voltage for $60 \mathrm{~min}$ and transferred onto a polyvinylidene fluoride membrane (Millipore, Bedford, MA, U.S.A.) using a semidry blot machine (Bio-Rad) at $5.5 \mathrm{~mA} / \mathrm{cm}^{2}$ for $60 \mathrm{~min}$. Blots were washed with PBS containing $0.1 \%$ (vol/vol) Tween-20 and probed with an anti-HA antibody (Thermo Fisher Scientific, Waltham, MA, U.S.A.). Anti-RNA polymerase monoclonal antibody (Neoclone, Madison, WI, U.S.A.) was used as a control. The resulting blots were incubated for $1 \mathrm{~min}$ in enhanced chemiluminescence reagent (GE Healthcare, Chicago, IL, U.S.A.) and detected using O-MAT X-ray film.

\section{B2H assay.}

Physical interaction between GcpA proteins was determined using a B2H system (Karimova et al. 1998). pUT18 and pKT25

Table 2. Oligonucleotide primers used in this study

\begin{tabular}{|c|c|c|}
\hline Primers & Sequences $\left(5^{\prime}-3^{\prime}\right)$ & Use \\
\hline fumA-A-XhoI & AATACTCGAGAGCGCGAATGAACATCC & fumA deletion \\
\hline fumA-B & GAAGCAGCTCCAGCCTACACCAATGGAAACGGATCTTG & $\ldots$ \\
\hline fumA-C & CTAAGGAGGATATTCATATGGACAAGGGCAACGAC & $\ldots$ \\
\hline fumA-D-NotI & AATATTATGCGGCCGCCCTGAAAGTGGATGTGC & $\ldots$ \\
\hline sdh-A-XhoI & AATACTCGAGGTATTAACCCTGTCCTGC & $s d h C D A B$ deletion \\
\hline$s d h-\mathrm{B}$ & GAAGCAGCTCCAGCCTACACCTTTGTAGATCCAGATTG & $\ldots$ \\
\hline$s d h-\mathrm{C}$ & CTAAGGAGGATATTCATATGTGGACGACCTGAATGA & $\ldots$ \\
\hline$s d h$-D-NotI & AATATTATGCGGCCGCGCGAAGCGTCTTTCGC & $\ldots$ \\
\hline fumA-for-XbaI & AATTCTAGACAGGGCTGTGGTTGATCGATA & fumA complementation \\
\hline fumA-rev-HindIII & TTTAAGCTTGGTTTGAAGGACAGGCCTGAC & $\ldots$ \\
\hline$s d h$-for-XbaI & AATTCTAGAAGGATGAACACAATTGCTCTC & sdhCDAB complementation \\
\hline$s d h$-rev-HindIII & TTTAAGCTTGTTACAAGCGTCTGAAAATCA & $\ldots$ \\
\hline gcpA-BTH-F-XbaI & AGGTCTAGAGGTGTATGAAATTATAATAACCCTAT & Bacterial two-hybrid system \\
\hline gсpA-BTH-Rc-KpnI & AAAGGTACC AGCTGGTGGGTATTCAAA & $\ldots$ \\
\hline 615 & TCGGGTATCGCTCTTGAAGGG & Transposon mutagenesis \\
\hline himar1 & CATTTAATACTAGCGACGCCATCT & $\ldots$ \\
\hline
\end{tabular}


plasmids containing $g c p A$ were electroporated into $E$. coli BTH101 cells. Cells were cultured in LB broth supplemented with $0.5 \mathrm{mM}$ isopropyl- $\beta{ }^{-} \mathrm{D}^{-1}$-thiogalactopyranoside, $\mathrm{Km}$ at $50 \mu \mathrm{g} / \mathrm{ml}$, and ampicillin at $100 \mu \mathrm{g} / \mathrm{ml}$, and with or without the addition of $0.4 \%(\mathrm{wt} / \mathrm{vol})$ sodium citrate at $30^{\circ} \mathrm{C}$ for $24 \mathrm{~h}$. A leucine zipper protein served as a positive control. Empty plasmids acted as the negative control. The extent of protein-protein interaction was analyzed by the $\beta$-galactosidase activity. In brief, $100 \mu \mathrm{l}$ of bacterial culture with $\mathrm{OD}_{600}=1.0$ was added to $900 \mu \mathrm{l}$ of Z-Buffer $\left(60 \mathrm{mM} \mathrm{Na}_{2} \mathrm{HPO}_{4}, 40 \mathrm{mM} \mathrm{NaH}_{2} \mathrm{PO}_{4}, 10 \mathrm{mM} \mathrm{KCl}\right.$, $1 \mathrm{mM} \mathrm{MgSO}_{4}$, and $50 \mathrm{mM}$ 2-mercaptoechanol; $\mathrm{pH}$ adjusted to 7.0). The enzymatic activity was started by adding $200 \mu \mathrm{l}$ of ortho-nitrophenyl- $\beta$-galactoside (4 $\mathrm{mg} / \mathrm{ml}$ in Z-Buffer) and samples were incubated at $30^{\circ} \mathrm{C}$ for $5 \mathrm{~min}$. To stop the reaction, $500 \mu \mathrm{l}$ of $1 \mathrm{M} \mathrm{Na}_{2} \mathrm{CO}_{3}$ was added and absorbance at $420 \mathrm{~nm}$ was read. $\beta$-Galactosidase activity (units per milliliter) was calculated according to the formula: $200 \times\left[\left(\mathrm{OD}_{420}-\mathrm{OD}_{420}\right.\right.$ in control tube)/minutes of incubation] $\times 10$.

\section{Virulence assay.}

The local leaf maceration assay was performed using the leaves of Chinese cabbage (B. campestris), as described previously (Yuan et al. 2015). In brief, $10 \mu \mathrm{l}$ of bacterial suspension in sterilized water at $10^{7} \mathrm{CFU} \mathrm{ml}^{-1}$ was inoculated into the wounds punched with a sterile pipette on the leaves. Five leaves were used for each strain. Inoculated Chinese cabbage leaves were kept in a growth chamber at $28^{\circ} \mathrm{C}$ with $100 \%$ relative humidity for $16 \mathrm{~h}$ before pictures were taken. To evaluate disease symptoms, APS ASSESS 1.0 software (Image Analysis Software for Plant Disease Quantification) was used to determine the leaf maceration areas.

The potato tuber infection assay was performed as previously described, with few modifications (Urbany and Neuhaus 2008). Bacterial suspensions $(10 \mu \mathrm{l})$ in sterilized water harboring $1.0 \times$ $10^{7} \mathrm{CFU} \mathrm{ml} \mathrm{m}^{-1}$ of cells were inoculated to the center of potato tubers ( $5 \mathrm{~mm}$ in thickness and $2 \mathrm{~cm}$ in diameter). Three tubers were used for each strain. The infected potato tubers were incubated at $28^{\circ} \mathrm{C}$ with $100 \%$ relative humidity for $24 \mathrm{~h}$. To quantify the disease symptoms, the weight of the potato tubers was measured. The macerated tissue was washed off in a stream of tap water and the weight of the remaining tissue was determined. The loss of weight represents the amount of macerated tissue.

\section{Sequence alignments.}

The nucleic acid sequences of CACHE domains were aligned using T-Coffee (Notredame et al. 2000), and edited manually. Sequences for alignment analysis were retrieved from ASAP and the NCBI GenBank database. Alignments were performed using the European Bioinformatics Institute (EMBL-EBI) webserver.

\section{Statistical analysis.}

Means and standard deviations of experimental results were calculated using Excel and the statistical analysis was performed using a two-tailed Student's $t$ test (Microsoft, Redmond, WA, U.S.A.).

\section{LITERATURE CITED}

Alfano, J. R., and Collmer, A. 1997. The type III (Hrp) secretion pathway of plant pathogenic bacteria: Trafficking harpins, Avr proteins, and death. J. Bacteriol. 179:5655-5662.

Antúnez-Lamas, M., Cabrera-Ordóñez, E., López-Solanilla, E., Raposo, R., Trelles-Salazar, O., Rodríguez-Moreno, A., and Rodríguez-Palenzuela, P. 2009. Role of motility and chemotaxis in the pathogenesis of Dickeya dadantii 3937 (ex Erwinia chrysanthemi 3937). Microbiology 155: 434-442.
Babujee, L., Apodaca, J., Balakrishnan, V., Liss, P., Kiley, P. J., Charkowski, A. O., Glasner, J. D., and Perna, N. T. 2012. Evolution of the metabolic and regulatory networks associated with oxygen availability in two phytopathogenic enterobacteria. BMC Genomics 13:110.

Bauer, D. W., Bogdanove, A. J., Beer, S. V., and Collmer, A. 1994. Erwinia chrysanthemi hrp genes and their involvement in soft rot pathogenesis and elicitation of the hypersensitive response. Mol. Plant-Microbe Interact. 7:573-581.

Bouhenni, R., Gehrke, A., and Saffarini, D. 2005. Identification of genes involved in cytochrome c biogenesis in Shewanella oneidensis, using a modified mariner transposon. Appl. Environ. Microbiol. 71:4935-4937.

Cohen-Ben-Lulu, G. N., Francis, N. R., Shimoni, E., Noy, D., Davidov, Y., Prasad, K., Sagi, Y., Cecchini, G., Johnstone, R. M., and Eisenbach, M. 2008. The bacterial flagellar switch complex is getting more complex. EMBO J. 27:1134-1144.

Collmer, A., and Keen, N. T. 1986. The role of pectic enzymes in plant pathogenesis. Annu. Rev. Phytopathol. 24:383-409.

Cui, Z., Yang, C.-H., Kharadi, R. R., Yuan, X., Sundin, G. W., Triplett, L. R., Wang, J., and Zeng, Q. 2019. Cell-length heterogeneity: A population-level solution to growth/virulence trade-offs in the plant pathogen Dickeya dadantii. PLoS Pathog. 15:e1007703.

Czajkowski, R., Perombelon, M. C., van Veen, J. A., and van der Wolf, J. M. 2011. Control of blackleg and tuber soft rot of potato caused by Pectobacterium and Dickeya species: A review. Plant Pathol. 60:999-1013.

Dacheux, D., Epaulard, O., de Groot, A., Guery, B., Leberre, R., Attree, I., Polack, B., and Toussaint, B. 2002. Activation of the Pseudomonas aeruginosa type III secretion system requires an intact pyruvate dehydrogenase $a c e A B$ operon. Infect. Immun. 70:3973-3977.

Datsenko, K. A., and Wanner, B. L. 2000. One-step inactivation of chromosomal genes in Escherichia coli K-12 using PCR products. Proc. Natl. Acad. Sci. U.S.A. 97:6640-6645.

Ding, Y., Liu, X., Chen, F., Di, H., Xu, B., Zhou, L., Deng, X., Wu, M., Yang, C.-G., and Lan, L. 2014. Metabolic sensor governing bacterial virulence in Staphylococcus aureus. Proc. Natl. Acad. Sci. U.S.A. 111:E4981-E4990.

Effantin, G., Rivasseau, C., Gromova, M., Bligny, R., and HugouvieuxCotte-Pattat, N. 2011. Massive production of butanediol during plant infection by phytopathogenic bacteria of the genera Dickeya and Pectobacterium. Mol. Microbiol. 82:988-997.

Giacalone, D., Smith, T. J., Collins, A. J., Sondermann, H., Koziol, L. J., and O'Toole, G. A. 2018. Ligand-mediated biofilm formation via enhanced physical interaction between a diguanylate cyclase and its receptor. MBio 9:e01254-18.

Hengge, R., Gründling, A., Jenal, U., Ryan, R., and Yildiz, F. 2015. Bacterial signal transduction by cyclic di-GMP and other nucleotide second messengers. J. Bacteriol. 198:15-26.

Hugouvieux-Cotte-Pattat, N., Condemine, G., and Shevchik, V. E. 2014 Bacterial pectate lyases, structural and functional diversity. Environ. Microbiol. Rep. 6:427-440.

Hugouvieux-Cotte-Pattat, N., Dominguez, H., and Robert-Baudouy, J. 1992. Environmental conditions affect transcription of the pectinase genes of Erwinia chrysanthemi 3937. J. Bacteriol. 174:7807-7818.

Jahn, C. E., Selimi, D. A., Barak, J. D., and Charkowski, A. O. 2011. The Dickeya dadantii biofilm matrix consists of cellulose nanofibres, and is an emergent property dependent upon the type III secretion system and the cellulose synthesis operon. Microbiology 157:2733-2744.

Jiang, X., Zghidi-Abouzid, O., Oger-Desfeux, C., Hommais, F., Greliche, N., Muskhelishvili, G., Nasser, W., and Reverchon, S. 2016. Global transcriptional response of Dickeya dadantii to environmental stimuli relevant to the plant infection. Environ. Microbiol. 18:3651-3672.

Karimova, G., Pidoux, J., Ullmann, A., and Ladant, D. 1998. A bacterial two-hybrid system based on a reconstituted signal transduction pathway. Proc. Natl. Acad. Sci. U.S.A. 95:5752-5756.

Kuo, C.-J., Wang, S.-T., Lin, C.-M., Chiu, H.-C., Huang, C.-R., Lee, D.-Y., Chang, G.-D., Chou, T.-C., Chen, J.-W., and Chen, C.-S. 2018. A multiomic analysis reveals the role of fumarate in regulating the virulence of enterohemorrhagic Escherichia coli. Cell Death Dis. 9:381.

Lebeau, A., Reverchon, S., Gaubert, S., Kraepiel, Y., Simond-Côte, E., Nasser, W., and Van Gijsegem, F. 2008. The GacA global regulator is required for the appropriate expression of Erwinia chrysanthemi 3937 pathogenicity genes during plant infection. Environ. Microbiol. 10:545-559.

Leggett, H. C., Cornwallis, C. K., Buckling, A., and West, S. A. 2017 Growth rate, transmission mode and virulence in human pathogens. Philos. Trans. R. Soc. B. 372:20160094.

Lerner, C. G., and Inouye, M. 1990. Low copy number plasmids for regulated low-level expression of cloned genes in Escherichia coli with blue/white insert screening capability. Nucleic Acids Res. 18:4631.

Ma, B., Hibbing, M. E., Kim, H.-S., Reedy, R. M., Yedidia, I., Breuer, J., Breuer, J., Glasner, J. D., Perna, N. T., Kelman, A., and Charkowski, A. O. 
2007. Host range and molecular phylogenies of the soft rot enterobacterial genera Pectobacterium and Dickeya. Phytopathology 97:1150-1163.

Massie, J. P., Reynolds, E. L., Koestler, B. J., Cong, J.-P., Agostoni, M., and Waters, C. M. 2012. Quantification of high-specificity cyclic diguanylate signaling. Proc. Natl. Acad. Sci. U.S.A. 109:12746-12751.

Matsumoto, H., Muroi, H., Umehara, M., Yoshitake, Y., and Tsuyumu, S. 2003. Peh production, flagellum synthesis, and virulence reduced in Erwinia carotovora subsp. carotovora by mutation in a homologue of cytR. Mol. Plant-Microbe Interact. 16:389-397.

Metcalf, W. W., Jiang, W., Daniels, L. L., Kim, S.-K., Haldimann, A., and Wanner, B. L. 1996. Conditionally replicative and conjugative plasmids carrying lacZ $\alpha$ for cloning, mutagenesis, and allele replacement in bacteria. Plasmid 35:1-13.

Meyer, S. E., Stewart, T. E., and Clement, S. 2010. The quick and the deadly: Growth vs virulence in a seed bank pathogen. New Phytol. 187: 209-216.

Notredame, C., Higgins, D. G., and Heringa, J. 2000. T-Coffee: A novel method for fast and accurate multiple sequence alignment. J. Mol. Biol. 302:205-217.

Paul, R., Weiser, S., Amiot, N. C., Chan, C., Schirmer, T., Giese, B., and Jenal, U. 2004. Cell cycle-dependent dynamic localization of a bacterial response regulator with a novel di-guanylate cyclase output domain. Genes Dev. 18:715-727.

Reverchon, S., and Nasser, W. 2013. Dickeya ecology, environment sensing and regulation of virulence programme. Environ. Microbiol. Rep. 5: 622-636.

Rietsch, A., and Mekalanos, J. J. 2006. Metabolic regulation of type III secretion gene expression in Pseudomonas aeruginosa. Mol. Microbiol. 59:807-820.

Río-Álvarez, I., Muñoz-Gómez, C., Navas-Vásquez, M., Martínez-García, P. M., Antúnez-Lamas, M., Rodríguez-Palenzuela, P., and LópezSolanilla, E. 2015. Role of Dickeya dadantii 3937 chemoreceptors in the entry to Arabidopsis leaves through wounds. Mol. Plant Pathol. 16: 685-698.

Römling, U., Galperin, M. Y., and Gomelsky, M. 2013. Cyclic di-GMP: The first 25 years of a universal bacterial second messenger. Microbiol. Mol. Biol. Rev. 77:1-52.

Ryan, R. P., Fouhy, Y., Lucey, J. F., Crossman, L. C., Spiro, S., He, Y.-W., Zhang, L.-H., Heeb, S., Cámara, M., Williams, P., and Dow, J. M. 2006. Cell-cell signaling in Xanthomonas campestris involves an HD-GYP domain protein that functions in cyclic di-GMP turnover. Proc. Natl. Acad. Sci. U.S.A. 103:6712-6717.

Sambrook, J., and Russell, D. W. 2006. Purification of nucleic acids by extraction with phenol:chloroform. Cold Spring Harbor Protoc. 2006.

Schirmer, T., and Jenal, U. 2009. Structural and mechanistic determinants of c-di-GMP signalling. Nat. Rev. Microbiol. 7:724-735.

Schmidt, A. J., Ryjenkov, D. A., and Gomelsky, M. 2005. The ubiquitous protein domain EAL is a cyclic diguanylate-specific phosphodiesterase: Enzymatically active and inactive EAL domains. J. Bacteriol. 187: 4774-4781.

Shimizu, K. 2013. Bacterial Cellular Metabolic Systems: Metabolic Regulation of a Cell System with 13C-metabolic Flux Analysis. Elsevier https://doi.org/10.1533/9781908818201

Suksomtip, M., Liu, P., Anderson, T., Tungpradabkul, S., Wood, D. W., and Nester, E. W. 2005. Citrate synthase mutants of Agrobacterium are attenuated in virulence and display reduced vir gene induction. J. Bacteriol. 187:4844-4852.

Takeuchi, K., Kiefer, P., Reimmann, C., Keel, C., Dubuis, C., Rolli, J., Vorholt, J. A., and Haas, D. 2009. Small RNA-dependent expression of secondary metabolism is controlled by Krebs cycle function in Pseudomonas fluorescens. J. Biol. Chem. 284:34976-34985.

Tamayo, R., Tischler, A. D., and Camilli, A. 2005. The EAL domain protein VieA is a cyclic diguanylate phosphodiesterase. J. Biol. Chem. 280: 33324-33330.

Tamir-Ariel, D., Navon, N., and Burdman, S. 2007. Identification of genes in Xanthomonas campestris pv. vesicatoria induced during its interaction with tomato. J. Bacteriol. 189:6359-6371.

Townsley, L., and Yildiz, F. H. 2015. Temperature affects c-di-GMP signalling and biofilm formation in Vibrio cholerae. Environ. Microbiol. 17:4290-4305.

Tuckerman, J. R., Gonzalez, G., Sousa, E. H., Wan, X., Saito, J. A., Alam, M., and Gilles-Gonzalez, M.-A. 2009. An oxygen-sensing diguanylate cyclase and phosphodiesterase couple for c-di-GMP control. Biochemistry 48:9764-9774.

Urbany, C., and Neuhaus, H. E. 2008. Citrate uptake into Pectobacterium atrosepticum is critical for bacterial virulence. Mol. Plant-Microbe Interact. 21:547-554.

Whiteley, C. G., and Lee, D.-J. 2015. Bacterial diguanylate cyclases: Structure, function and mechanism in exopolysaccharide biofilm development. Biotechnol. Adv. 33:124-141.

Yang, C.-H., Gavilanes-Ruiz, M., Okinaka, Y., Vedel, R., Berthuy, I., Boccara, M., Chen, J. W.-T., Perna, N. T., and Keen, N. T. 2002. hrp genes of Erwinia chrysanthemi 3937 are important virulence factors. Mol. Plant-Microbe Interact. 15:472-480.

Yang, S., Peng, Q., Zhang, Q., Yi, X., Choi, C. J., Reedy, R. M., Charkowski, A. O., and Yang, C.-H. 2008. Dynamic regulation of GacA in type III secretion, pectinase gene expression, pellicle formation, and pathogenicity of Dickeya dadantii (Erwinia chrysanthemi 3937). Mol. Plant-Microbe Interact. 21:133-142.

Yi, X., Yamazaki, A., Biddle, E., Zeng, Q., and Yang, C. H. 2010. Genetic analysis of two phosphodiesterases reveals cyclic diguanylate regulation of virulence factors in Dickeya dadantii. Mol. Microbiol. 77: 787-800.

Yuan, X., Khokhani, D., Wu, X., Yang, F., Biener, G., Koestler, B. J., Raicu, V., He, C., Waters, C. M., Sundin, G. W., Tian, F., and Yang, C.-H. 2015. Cross-talk between a regulatory small RNA, cyclic-di-GMP signalling and flagellar regulator FlhDC for virulence and bacterial behaviours. Environ. Microbiol. 17:4745-4763.

Yuan, X., Tian, F., He, C., Severin, G. B., Waters, C. M., Zeng, Q., Liu, F., and Yang, C. H. 2018. The diguanylate cyclase GcpA inhibits the production of pectate lyases via the H-NS protein and RsmB regulatory RNA in Dickeya dadantii. Mol. Plant Pathol. 19:1873-1886.

Yuan, X., Zeng, Q., Khokhani, D., Tian, F., Severin, G. B., Waters, C. M., Xu, J., Zhou, X., Sundin, G. W., Ibekwe, A. M., Liu, F., and Yang, C. H. 2019. A feed-forward signalling circuit controls bacterial virulence through linking cyclic di-GMP and two mechanistically distinct sRNAs, ArcZ and RsmB. Environ. Microbiol. 21:2755-2771.

Zeng, Q., Ibekwe, A. M., Biddle, E., and Yang, C.-H. 2010. Regulatory mechanisms of exoribonuclease PNPase and regulatory small RNA on T3SS of Dickeya dadantii. Mol. Plant-Microbe Interact. 23:1345-1355. 